\title{
Human Immunodeficiency Virus Infection and Hodgkin's Lymphoma in South Africa: An Emerging Problem
}

\author{
Moosa Patel, Vinitha Philip, and Fatima Fazel \\ Division of Clinical Haematology, Department of Medicine, Chris Hani Baragwanath Hospital and the University of \\ the Witwatersrand, P.O. Box 96092, Brixton, Johannesburg 2019, South Africa \\ Correspondence should be addressed to Moosa Patel, moosa.patel@wits.ac.za
}

Received 11 August 2010; Accepted 23 December 2010

Academic Editor: Myriam Labopin

Copyright ( 2011 Moosa Patel et al. This is an open access article distributed under the Creative Commons Attribution License, which permits unrestricted use, distribution, and reproduction in any medium, provided the original work is properly cited.

Hodgkin's lymphoma (HL) occurs with increasing frequency in human-immunodeficiency-virus-(HIV-) infected individuals. The natural history and behaviour of HIV-HL is different, being more atypical and aggressive. The association between HIV and HL appears to be primarily EBV driven. HAART use does not significantly impact on the incidence of HL. Indeed, the risk of HL has increased in the post-HAART era. However, the advent of HAART has brought renewed hope, allowing standard therapeutic options to be used more optimally, with better treatment outcomes. Despite the renewed optimism, the overall survival of HIV-HL patients remains less favourable than that in HIV-seronegative patients. This is particularly true in sub-Saharan Africa, where there is a significant burden of HIV/AIDS and where more than half the patients are HAART naive at diagnosis of HL. The similarities and differences of a South African cohort of HIV-HL are presented in this paper.

\section{Introduction}

Human immunodeficiency virus (HIV) infection is known to be associated with an increased risk of Hodgkin's lymphoma (HL), based on linkage and cohort studies. The relative risk is now approximately 10 -fold higher compared with the general population [1-5]. Earlier studies suggest that the HIV risk differed between the European and American cohorts with intravenous drug use being predominant in the Italian and Spanish patients compared to the American, where it was noted mainly in homosexual men $[1,2,5,6]$. In sub-Saharan Africa, the major risk of acquiring HIV occurs with heterosexual relationships. This is true for all the patients in the series presented here (unpublished personal data; see Table 1).

HL occurring in the setting of immunodeficiency is generally aggressive, characterized by advanced-stage disease, frequent constitutional symptoms, less favourable histology, more frequent bone marrow involvement, and a poorer prognosis compared to immunocompetent individuals.

With the advent of HAART in 1996, the AIDSrelated morbidity, particularly with respect to opportunistic infections, has decreased and the survival of HIV/AIDS patients has increased. HAART has allowed the use of standard therapeutic options to be delivered to seropositive patients in a more optimal manner, bringing about renewed optimism in the management of such patients. HAART use is associated with higher CD4 T-cell counts and enhanced immunity. Carbone et al. in 2009 [5] suggest that the improved CD4 T-cell count that occurs after HAART use provides antiapoptotic pathways and mechanisms for immune escape by tumour cells, thus resulting in an increased risk of HL [5].

A 20-year cohort study has shown that with the advent of antiretroviral therapy, ADCs (AIDS-defining cancers) continue to fall, but the rates of NADCs (non-AIDS defining cancers) are on the increase. The authors conclude that this increase appears to be more related to the aging of the HIV population rather than the antiretroviral therapy and its effect on the CD4 T-cell count [7].

This paper will focus on the epidemiology, pathogenesis, clinical presentation, and management of HL in the setting of HIV. The similarities and differences as observed in Southern African patients will also be highlighted. 


\section{Epidemiology}

With the advent of antiretroviral therapy, ADCs (AIDSdefining cancers) continue to fall, but the rates of NADCs (non-AIDS defining cancers) such as HL, anal carcinoma, lung carcinoma, and skin cancers are on the increase [7]. With HL, there is a noticeably increasing relative risk of approximately 10 -fold, compared with the general population [1-6].

The epidemiology of HIV-HL is comprehensively reviewed by Carbone et al. in 2009 [5]. In this excellent review, the authors summarise the findings of several epidemiological studies conducted in the last two decades, which strongly support the evidence that HIV-positive individuals have a higher risk of developing HL compared to their HIV-negative counterparts. This is in contrast to HIV-NHL or HIV-Kaposi's sarcoma (where the incidence of the disease has decreased significantly after the introduction of HAART). Thus, despite the benefit of HAART, which improves immunity and decreases the risk of opportunistic infections, there is a paradoxically increased risk of HL [5].

More than two thirds of all people with HIV live in subSaharan Africa, and South Africa is home to the world's largest population of people living with HIV- 5.7 million in 2007 [8]. Early studies in the mid 1990's and early 2000's in South Africa (including patients from the Chris Hani Baragwanath Hospital $(\mathrm{CHBH})$ - a tertiary, public sector hospital, linked to the University of the Witwatersrand, and located in Soweto, Johannesburg) showed only a modest increase of Non-Hodgkin's Lymphoma (NHL) in seropositive individuals, with odds ratios of 4.8, 5, and 5.9, respectively [9-11].

However, at $\mathrm{CHBH}$, since 2002, there has been a clearly noticeable increase in the proportion of seropositive patients with NHL (i.e., $60-70 \%$ of newly diagnosed patients with NHL are HIV positive), and furthermore, there has been a significant increase in the total number of patients with NHL since 2002 (from 20-30 new patients per year to 70-80 patients per year) [12]. Indeed, NHL is now the commonest haematological malignancy in South Africa, in the current HIV/AIDS era.

With respect to Hodgkin's lymphoma (HL), the data is less dramatic but is becoming more significant. In a study by Stein et al. in 2008 [11], the percentage of seropositivity of HL in a South African cohort (which included patients from $\mathrm{CHBH})$ was $19.5 \%(\mathrm{OR}=1.6,95 \% \mathrm{CI}=1.0-2.7)$, during the period from 1995 to 2004 . However, in the last 4 years, at our single institution, $\mathrm{CHBH}$, the percentage of seropositivity has been greater than $50 \%$ (unpublished personal data) and the number of patients over the years has been gradually increasing (doubled compared to an earlier series in the late 1980's and early 1990's) [13]. In the last 2 years (July 2008 to June 2010), a total of 43 consecutive adult black patients with HL were diagnosed at this single institution. Of these patients, 29 were HIV seropositive (67\%) and $14(33 \%)$ were seronegative. The clinical characteristics of this retrospective review of the seropositive patients are depicted in Table 1.

\section{Pathogenesis}

HL is characterized by an admixture of a minority of neoplastic Reed-Sternberg (RS) cells and a reactive, mixed inflammatory infiltrate of lymphocytes, plasma cells, eosinophils, and histiocytes. Cytokines and chemokines are produced by either the RS cells or the reactive cells. The cytokine production may explain the presence and maintenance of an impaired immune response, while the chemokines (cytokines with chemoattractant properties) play a role in leucocyte trafficking, attract chemokine receptor CCR4expressing Th-2 cells and T regulatory cells, and allow a favourable environment for survival of RS cells [14-16]. Cross-talk between the RS cells and reactive cells mediated by cytokines such as IL-13, IL-17, IL-10, transforming growth factor beta, and chemokines,principally CCL17 (thymusand activation-regulated chemokine, TARC) and CCL22 (macrophage-derived chemokine, MDC), leads to an environment where RS cells are able to proliferate, escape from apoptosis, and survive host antitumour defense [14-16]. The CD4+ $\mathrm{T}$ cells surrounding the neoplastic cells in HL are CD45RO+/CD45RA-/CD45RB ${ }^{\mathrm{dim}}$, suggesting a memory Th2 phenotype [17].

HIV-associated immunosuppression is a state that permits the unchecked and uncontrolled proliferation of Epstein-Barr virus (EBV) infection. EBV has been implicated in the aetiopathogenesis of classic HL. EBV-transforming proteins, such as latent membrane protein-1 (LMP-1), is expressed in virtually all HIV-HL patients [18-20]. The expression of EBV-LMP-1 is important in the pathogenesis of HIV-HL. LMP-1 expression by EBV-infected RS cells represents the principal mechanism for constitutive nuclear factor $\mathrm{NF} \kappa \mathrm{B}$ activity, which confers an apoptosis-resistant phenotype to the RS cells $[19,20]$. EBV-immortalized B cells also produce CCL17 and CCL22 through LMP-1-mediated activation of $\mathrm{NF} \kappa \mathrm{B}$ [21].

RS cells represent transformed B cells (postgerminal center $\mathrm{B}$ cells) that originate from preapoptotic germinal center B cells. They express LMP-1 and display a BCL6-/ CD138+/MUM1/IRF4+ (Interferon Regulatory Factor-4) phenotype [19, 22, 23]. In addition, LMP2A and EBNA-1 may also contribute to the development of the RS cells, and they are expressed in the RS cells of this tumour $[18,20]$. LMP2A may promote the survival of the "crippled" germinal center B cells, thereby aiding in their development [24].

\section{Clinical Presentation and Management}

HIV-seropositive patients with HL generally pursue a more aggressive clinical course than seronegative patients. The behaviour of the disease is different, and based on a number of studies $[5,6,25-32]$, the following parameters were noted: more advanced-stage disease (III and IV), 74-92\%, more frequent systemic B symptoms, 70-96\%, more frequent involvement of extranodal sites, 17-62\%, with bone marrow involvement being the most common extranodal site, $40-59 \%$, followed by involvement of the liver, $17-40 \%$, and spleen, $20-30 \%$. Most of the patients $(>80 \%)$ were males. 
TABLE 1: Characteristics of patients $(n=29)$ with HIV-associated Hodgkin's lymphoma seen at the Chris Hani Baragwanath Hospital (July 2008 to June 2010).

\begin{tabular}{|c|c|c|}
\hline Patient characteristics & Number & $\%$ \\
\hline \multicolumn{3}{|l|}{ Median age (range) $\_38$ years $(21-64)$ mean age -37 years $(21-64)$} \\
\hline \multicolumn{3}{|l|}{ Gender } \\
\hline Male & 15 & 52 \\
\hline Female & 14 & 48 \\
\hline \multicolumn{3}{|l|}{ Male: female ratio $1.1: 1$} \\
\hline \multicolumn{3}{|l|}{ ECOG performance status } \\
\hline $0-2$ & 18 & 62 \\
\hline $3-4$ & 11 & 38 \\
\hline “B” symptoms & 27 & 93 \\
\hline \multicolumn{3}{|l|}{ Bone marrow involvement } \\
\hline Yes & $10(26)$ & 38 \\
\hline No & $16(26)$ & 62 \\
\hline Unknown & 3 & 11 \\
\hline \multicolumn{3}{|l|}{ Stage of lymphoma } \\
\hline I-II & $5(28)$ & 18 \\
\hline III-IV & $23(28)$ & 82 \\
\hline Unclear & 1 & 4 \\
\hline \multicolumn{3}{|l|}{ Histology } \\
\hline Mixed cellularity & $13(24)$ & 54 \\
\hline Nodular sclerosis & $8(24)$ & 33 \\
\hline Lymphocyte depleted & $2(24)$ & 8 \\
\hline Lymphocyte rich & $1(24)$ & 4 \\
\hline Unclassifiable/unknown & 5 & 17 \\
\hline \multicolumn{3}{|l|}{ CD4 count in $\mu \mathrm{l}($ range in $\mu \mathrm{l})-$ mean CD4 $=176(10-407)$} \\
\hline$>200 / \mu 1$ & $11(28)$ & 39 \\
\hline$<200 / \mu 1$ & $17(28)$ & 61 \\
\hline$<100 / \mu 1$ & 9 & 31 \\
\hline$<50 / \mu \mathrm{l}$ & 6 & 21 \\
\hline Unknown & 1 & 3 \\
\hline \multicolumn{3}{|l|}{ Risk factor for hiv infection } \\
\hline Heterosexual relation & 29 & 100 \\
\hline Other (intravenous drug use, homosexual relation) & 0 & \\
\hline \multicolumn{3}{|l|}{ Duration of hiv } \\
\hline$>1$ Year & 11 & 38 \\
\hline$<1$ Year & 18 & 62 \\
\hline \multicolumn{3}{|l|}{ Use of antiretroviral therapy at diagnosis } \\
\hline Yes & 13 & 45 \\
\hline No & 16 & 55 \\
\hline True extranodal involvement (excluding liver, spleen, and bone marrow) & 5 & 17 \\
\hline Liver involvement & 13 & 45 \\
\hline Splenic involvement & 8 & 28 \\
\hline Tuberculosis & 17 & 59 \\
\hline Active disease & 11 & 38 \\
\hline Past infection & 6 & 21 \\
\hline \multicolumn{3}{|l|}{ Outcome } \\
\hline Alive & 15 & 52 \\
\hline Dead & 11 & 38 \\
\hline Ltfu (lost to follow up) & 3 & 10 \\
\hline
\end{tabular}


TABle 2: Salient differences between HIV-HL in South Africa and other reported series.

\begin{tabular}{|c|c|c|}
\hline & $\begin{array}{l}\text { South Africa (Chris Hani Baragwanath } \\
\text { Hospital-CHBH) }\end{array}$ & Other reported series \\
\hline Gender & $\mathrm{M}: \mathrm{F}$ ratio, $1.1: 1$ & Majority male (>80\%) \\
\hline Median CD4 count & $176 / \mu 1$ & $240-306 / \mu 1$ (In different series) \\
\hline Risk factors & Heterosexual relationship & Intravenous drug use and homosexual relationship \\
\hline \multirow{2}{*}{$\begin{array}{l}\text { Diagnosis and duration of } \\
\text { HIV }\end{array}$} & New diagnosis of HIV, $41 \%$ & \multirow[t]{2}{*}{ Majority-established or long-standing HIV } \\
\hline & Duration of HIV <1 Year, $62 \%$ & \\
\hline \multirow{2}{*}{ ARV's at diagnosis } & $45 \%$ on ARV'S & \multirow[t]{2}{*}{$71-80 \%$ on ARV'S } \\
\hline & 55\% ARV naive & \\
\hline Tuberculosis & $\begin{array}{l}38 \% \text { Active disease, } 21 \% \text { past, documented } \\
\text { disease }\end{array}$ & Unknown (low prevalence) \\
\hline $\begin{array}{l}\text { Prognosis and overall } \\
\text { survival }\end{array}$ & Generally unfavourable & $\begin{array}{l}\text { Less favourable than HIV negative HL. Improving with } \\
\text { standard chemotherapy and concomitant HAART }\end{array}$ \\
\hline
\end{tabular}

The median age at presentation was approximately 34 years. The median CD4 count was mostly in the intermediate range of $240-306 / \mu \mathrm{L}[5,6,25-32]$. Compared to HIV-negative HL, where nodular sclerosis is the dominant histological subtype, mixed cellularity is most commonly encountered in HIVHL, 33-53\% [5, 13, 30-32]. Nodular sclerosis is the second most common histological subtype in HIV-HL, 24-31\%. However, with more severe immunosuppression, nodular sclerosis becomes infrequent [33]. There is also an increasing number of patients with lymphocyte-depleted histology, 1420\%, in HIV-HL [5, 30-32].

Based on the Italian Cooperative Group on AIDS and Tumors (GICAT), in comparison with patients who were HAART naive, patients receiving HAART before the onset of HL are older, have less B symptoms, have higher leukocyte and neutrophil counts, and have a higher haemoglobin level [30].

The characteristics of the patients with HIV-associated $\mathrm{HL}$ seen at $\mathrm{CHBH}$ over a 2 -year period are depicted in Table 1. There are some striking similarities and differences when comparing this cohort with other published studies outside of Africa. The median age at presentation is similar. There is no striking male predominance in our patients. Conversely, the male to female ratio is almost equal at $1.1: 1$. None of our patients have homosexual contacts or are intravenous drug users. This is different from other series where homosexuality and intravenous drug use are significant, documented risk groups $[1,2,5,6,30,31]$. The presentation with advanced-stage disease, more frequent systemic B symptoms, more frequent involvement of extranodal sites, and the histological patterns of disease is similar to that reported in the literature (see above). The median CD4 count of $176 / \mu \mathrm{L}$ is generally lower in our patients, although there are series reported of HIV-HL with median CD4 counts of $<200 / \mu \mathrm{L}$ [31]. In our series, $12 / 29(41 \%)$ of the patients had newly diagnosed HIV at the time of the diagnosis of HL. In $62 \%$ of the patients, the duration of the diagnosis of HIV (including new patients) was $<1$ year. Only $45 \%$ of the patients were on antiretroviral therapy at diagnosis of $\mathrm{HL}$, compared to $71-80 \%$ in other series $[5,30,31]$. A further striking difference is the high proportion of patients with
Tuberculosis in our series, 59\% (38\% with active disease and $21 \%$ with past, documented disease). The high prevalence of tuberculosis may be a reflection of the more severe immunosuppression in our patients, the delay in diagnosis of HIV, and hence the absence of antiretroviral therapy use at diagnosis, and the common occurrence of tuberculosis in the general population. The presence of tuberculosis, often in a disseminated fashion, impacts adversely on the clinical outcome of our patients.

The salient differences between HIV-HL in South Africa and other reported series outside of Africa (mostly from Europe and the USA) [5, 6, 25-32] are detailed in Table 2 above.

The management of HIV-HL is challenging because of the frequency of infections, likelihood of organ dysfunction due to HIV, more frequent involvement of the bone marrow, increased myelosuppression, potential interactions of the antiretrovirals and anti-infectives with chemotherapy, the advanced and widespread nature of the disease at presentation, and the preponderance of less favourable histological subtypes. Treatment approaches include vigorous supportive care (HAART, antivirals, antifungals, neutrophilstimulating growth factors), together with standard multiagent chemotherapy.

Chemotherapy regimens for HIV-HL such as ABVD, EBVP, BEACOPP, MOPP/ABV hybrid, and Stanford V are feasible and can be delivered with concomitant HAART. The AIDS Clinical Trials Group (ACTG) treated 21 patients with ABVD for 4-6 cycles and primary use of G-CSF. Antiretroviral therapy was not used. The complete remission rate, on intent-to-treat analysis was $43 \%$ with an overall objective response rate of $62 \%$. Median survival for all patients was 18 months [34]. In a more recent Spanish study, 62 patients with HIV-HL received the standard, full-dose ABVD and HAART. 87\% achieved a complete remission. The 5-year overall survival (OS) and event-free survival (EFS) probabilities were 76 and $71 \%$, respectively. The immunological response to HAART had a positive impact on OS $(P=.002)$ and $\operatorname{EFS}(P=.001)$ [35]. The use of HAART substantially improves the overall survival in HIVassociated HL. This is due to a decrease in the incidence 
of opportunistic infections, the ability to deliver more appropriate and aggressive chemotherapy on schedule, and to the less aggressive presentation of lymphoma in patients on HAART, in comparison with those lymphomas that arise in patients who never received HAART [6, 25-27, 29]. In the study by Hentrich et al., in 2006, 34/59 patients receiving HAART $(n=34)$ had a significantly better 2 -year overall survival than those not receiving HAART (74\% versus 30\%, $P<.001)$ [36]. The advent of HAART also allows for more aggressive treatment options such as VEBEP [37], BEACOPP [38], and Stanford V [39] and the use of highdose chemotherapy and autologous stem cell transplantation (ASCT) in selected patients [40, 41]. However, in general, response rates and cure rates are lower than in HIVseronegative patients, despite the substantial progress made in the last decade. The challenge at present is to optimise the use of standard approaches as used in HIV-negative HL. Once this is established, evaluation of experimental and newer therapies should follow.

\section{Conclusion}

HIV is associated with an increased risk of HL. Although the risk is much less than with NHL, the risk appears to be increasing with time, with HL now being regarded among the most common NADCs. The increased incidence cannot be explained by more intensive surveillance or diagnostic errors [42]. The association, which was being largely coincidental (overlapping and similar age group for both HL and HIV) may now be increasingly causal, with the most plausible explanation being attributed to the pathogenetic role of Epstein-Barr virus infection. Therapy of HIV-associated HL entails using the same therapeutic approaches as in seronegative HL, including standard chemotherapy regimens such as ABVD, and in the salvage setting, autologous stem cell transplantation in selected patients. In general, the prognosis and overall survival are poorer in HIV-HL compared to HIV-negative HL. Importantly, the concomitant use of antiretroviral agents and prophylaxis against certain opportunistic infections such as Pneumocystis jiroveci pneumonia, as well as the liberal use of growth factors (granulocyte colony stimulating factor) and other supportive measures, constitutes an important aspect of supportive therapy and has contributed to an improvement in prognosis. The early recognition and treatment of tuberculosis cannot be overemphasized in settings where tuberculosis is endemic. Newer specific treatment approaches for HL may become necessary to improve survival, as the association with HIV increases and becomes clearer in the future. For the present, HIV-associated HL remains an ongoing challenge.

\section{References}

[1] N. A. Hessol, M. H. Katz, J. Y. Liu, S. P. Buchbinder, C. J. Rubino, and S. D. Holmberg, "Increased incidence of Hodgkin disease in homosexual men with HIV infection," Annals of Internal Medicine, vol. 117, no. 4, pp. 309-311, 1992.

[2] D. W. Lyter, J. Bryant, R. Thackeray, C. R. Rinaldo, and L. A. Kingsley, "Incidence of human immunodeficiency virus-related and nonrelated malignancies in a large cohort of homosexual men," Journal of Clinical Oncology, vol. 13, no. 10, pp. 2540-2546, 1995.

[3] J. J. Goedert, T. R. Coté, P. Virgo et al., "Spectrum of AIDSassociated malignant disorders," The Lancet, vol. 351, no. 9119, pp. 1833-1839, 1998.

[4] M. Herida, M. Mary-Krause, R. Kaphan et al., "Incidence of non-AIDS-defining cancers before and during the highly active antiretroviral therapy era in a cohort of human immunodeficiency virus-infected patients," Journal of Clinical Oncology, vol. 21, no. 18, pp. 3447-3453, 2003.

[5] A. Carbone, A. Gloghini, D. Serraino, and M. Spina, "HIVassociated Hodgkin lymphoma," Current Opinion in HIV and AIDS, vol. 4, no. 1, pp. 3-10, 2009.

[6] U. Tirelli, D. Errante, R. Dolcetti et al., "Hodgkin's disease and human immunodeficiency virus infection: clinicopathologic and virologic features of 114 patients from the Italian Cooperative group on AIDS and Tumors," Journal of Clinical Oncology, vol. 13, no. 7, pp. 1758-1767, 1995.

[7] N. Crum-Cianflone, K. H. Hullsiek, V. Marconi et al., "Trends in the incidence of cancers among HIV-infected persons and the impact of antiretroviral therapy: a 20-year cohort study," AIDS, vol. 23, no. 1, pp. 41-50, 2009.

[8] UNAIDS, Report on the Global AIDS Epidemic, UNAIDS, Geneva, Switzerland, 2008.

[9] F. Sitas, W. R. Bezwoda, V. Levin et al., "Association between human immunodeficiency virus type 1 infection and cancer in the black population of Johannesburg and Soweto, South Africa," British Journal of Cancer, vol. 75, no. 11, pp. 17041707, 1997.

[10] F. Sitas, R. Pacella-Norman, H. Carrara et al., "The spectrum of HIV-1 related cancers in South Africa," International Journal of Cancer, vol. 88, no. 3, pp. 489-492, 2000.

[11] L. Stein, M. I. Urban, D. O'Connell et al., "The spectrum of human immunodeficiency virus-associated cancers in a South African black population: results from a case-control study, 1995-2004," International Journal of Cancer, vol. 122, no. 10, pp. 2260-2265, 2008.

[12] M. Patel, V. Philip, D. Turton et al., "The impact of HIV on non-Hodgkin's lymphoma at Chris Hani Baragwanath Hospital," Haematologica, vol. 92, no. s1, p. 273, 2007.

[13] M. Patel, "Haematology," in Baragwanath Hospital 50 yearsA Medical Miscellany, K. Huddle and A. Dubb, Eds., pp. 173190, Ultra Litho, 1994.

[14] S. Takegawa, Z. Jin, T. Nakayama et al., "Expression of CCL17 and CCL22 by latent membrane protein 1-positive tumor cells in age-related Epstein-Barr virus-associated B-cell lymphoproliferative disorder," Cancer Science, vol. 99, no. 2, pp. 296-302, 2008.

[15] M. Niens, L. Visser, I. M. Nolte et al., "Serum chemokine levels in Hodgkin lymphoma patients: highly increased levels of CCL17 and CCL22," British Journal of Haematology, vol. 140, no. 5, pp. 527-536, 2008.

[16] E. Maggio, A. van den Berg, A. Diepstra, J. Kluiver, L. Visser, and S. Poppema, "Chemokines, cytokines and their receptors in Hodgkin's lymphoma cell lines and tissues," Annals of Oncology, vol. 13, supplement 1, pp. 52-56, 2002.

[17] S. Poppema, R. Lai, L. Visser, and X. J. Yan, "CD45 (leucocyte common antigen) expression in T and B lymphocyte subsets," Leukemia and Lymphoma, vol. 20, no. 3-4, pp. 217-222, 1996.

[18] L. S. Young and A. B. Rickinson, "Epstein-Barr virus: 40 years on,” Nature Reviews Cancer, vol. 4, no. 10, pp. 757-768, 2004. 
[19] A. Carbone, A. Gloghini, L. M. Larocca et al., "Human immunodeficiency virus-associated Hodgkin's disease derives from post-germinal center B cells," Blood, vol. 93, no. 7, pp. 2319-2326, 1999.

[20] A. Carbone, A. Gloghini, and G. Dotti, "EBV-associated lymphoproliferative disorders: classification and treatment," Oncologist, vol. 13, no. 5, pp. 577-585, 2008.

[21] T. Nakayama, K. Hieshima, D. Nagakubo et al., "Selective induction of Th2-attracting chemokines CCL17 and CCL22 in human B cells by latent membrane protein 1 of Epstein-Barr virus," Journal of Virology, vol. 78, no. 4, pp. 1665-1674, 2004.

[22] U. Klein and R. Dalla-Favera, "Germinal centres: role in B-cell physiology and malignancy," Nature Reviews Immunology, vol. 8, no. 1, pp. 22-33, 2008.

[23] A. Carbone, A. Gloghini, L. M. Larocca et al., "Expression profile of MUM1/IRF4, BCL-6, and CD138/syndecan-1 defines novel histogenetic subsets of human immunodeficiency virusrelated lymphomas," Blood, vol. 97, no. 3, pp. 744-751, 2001.

[24] C. Mancao and W. Hammerschmidt, "Epstein-Barr virus latent membrane protein $2 \mathrm{~A}$ is a $\mathrm{B}$-cell receptor mimic and essential for B-cell survival," Blood, vol. 110, no. 10, pp. 37153721, 2007.

[25] U. Tirelli, E. Vaccher, D. Serraino et al., "Comparison of presenting clinical and laboratory findings of patients with persistent generalized lymphadenopathy (PGL) syndrome and malignant lymphoma (ML)," Haematologica, vol. 72, no. 6, pp. 563-565, 1987.

[26] J. M. Andrieu, S. Roithmann, J. M. Tourani et al., "Hodgkin's disease during HIV1 infection: the French registry experience," Annals of Oncology, vol. 4, no. 8, pp. 635-641, 1993.

[27] R. Rubio, "Hodgkin's disease associated with human immunodeficiency virus infection: a clinical study of 46 cases," Cancer, vol. 73, no. 9, pp. 2400-2407, 1994.

[28] A. García-Noblejas, S. Nieto, R. Liberal et al., "Intracerebral Hodgkin's lymphoma in a patient with human immunodeficiency virus," Haematologica, vol. 92, no. 6, pp. e72-e73, 2007.

[29] E. Vaccher, M. Spina, R. Talamini et al., "Improvement of systemic human immunodeficiency virus-related nonHodgkin lymphoma outcome in the era of highly active antiretroviral therapy," Clinical Infectious Diseases, vol. 37, no. 11, pp. 1556-1564, 2003.

[30] E. Chimienti, M. Spina, R. Gastaldi et al., "Clinical characteristics and outcome of 290 patients (pts) with Hodgkin's disease and HIV infection (HD-HIV) in pre and HAART (highly active antiretroviral therapy) era," Annals of Oncology, vol. 19, p. iv136, 2008, abstract 168 .

[31] J. Berenguer, P. Miralles, J. M. Ribera et al., "Characteristics and outcome of AIDS-related Hodgkin lymphoma before and after the introduction of highly active antiretroviral therapy," Journal of Acquired Immune Deficiency Syndromes, vol. 47, no. 4, pp. 422-428, 2008.

[32] L. D. R. Thompson, M. S. I. Fisher, W. S. Chu, A. Nelson, and S. L. Abbondanzo, "HIV-associated Hodgkin lymphoma: a clinicopathologic and immunophenotypic study of 45 cases," American Journal of Clinical Pathology, vol. 121, no. 5, pp. 727738, 2004.

[33] R. J. Biggar, E. S. Jaffe, J. J. Goedert, A. Chaturvedi, R. Pfeiffer, and E. A. Engels, "Hodgkin lymphoma and immunodeficiency in persons with HIV/AIDS," Blood, vol. 108, no. 12, pp. 37863791, 2006.

[34] A. M. Levine, P. Li, T. Cheung et al., "Chemotherapy consisting of doxorubicin, bleomycin, vinblastine, and dacarbazine with granulocyte-colony-stimulating factor in HIV-infected patients with newly diagnosed Hodgkin's disease: a prospective, multi-institutional AIDS Clinical Trials Group Study (ACTG 149)," Journal of Acquired Immune Deficiency Syndromes, vol. 24, no. 5, pp. 444-450, 2000.

[35] B. Xicoy, J. M. Ribera, P. Miralles et al., "Results of treatment with doxorubicin, bleomycin, vinblastine and dacarbazine and highly active antiretroviral therapy in advanced stage, human immunodeficiency virus-related Hodgkin's lymphoma," Haematologica, vol. 92, no. 2, pp. 191-198, 2007.

[36] M. Hentrich, L. Maretta, K. U. Chow et al., "Highly active antiretroviral therapy (HAART) improves survival in HIVassociated Hodgkin's disease: results of a multicenter study," Annals of Oncology, vol. 17, no. 6, pp. 914-919, 2006.

[37] M. Spina, G. Rossi, A. Antinori et al., "VEBEP regimen and highly active antiretroviral therapy (HAART) in patients (pts) with HD and HIV infection (HD-HIV)," Annals of Oncology, vol. 19, p. iv152, 2008, abstract 227.

[38] P. Hartmann, U. Rehwald, B. Salzberger et al., "BEACOPP therapeutic regimen for patients with Hodgkin's disease and HIV infection," Annals of Oncology, vol. 14, no. 10, pp. 15621569, 2003.

[39] M. Spina, J. Gabarre, G. Rossi et al., "Stanford V regimen and concomitant HAART in 59 patients with Hodgkin disease and HIV infection," Blood, vol. 100, no. 6, pp. 1984-1988, 2002.

[40] A. Krishnan, A. Molina, J. Zaia et al., "Durable remissions with autologous stem cell transplantation for high-risk HIVassociated lymphomas," Blood, vol. 105, no. 2, pp. 874-878, 2005.

[41] T. R. Spitzer, R. F. Ambinder, J. Y. Lee et al., "Dosereduced busulfan, cyclophosphamide, and autologous stem cell transplantation for human immunodeficiency virusassociated lymphoma: AIDS Malignancy Consortium Study 020," Biology of Blood and Marrow Transplantation, vol. 14, no. 1, pp. 59-66, 2008.

[42] J. M. Connors, "Challenging problems: coincident pregnancy, HIV infection, and older age," Hematology, pp. 334-339, 2008. 


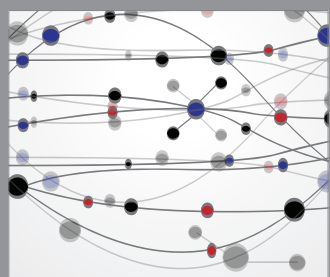

The Scientific World Journal
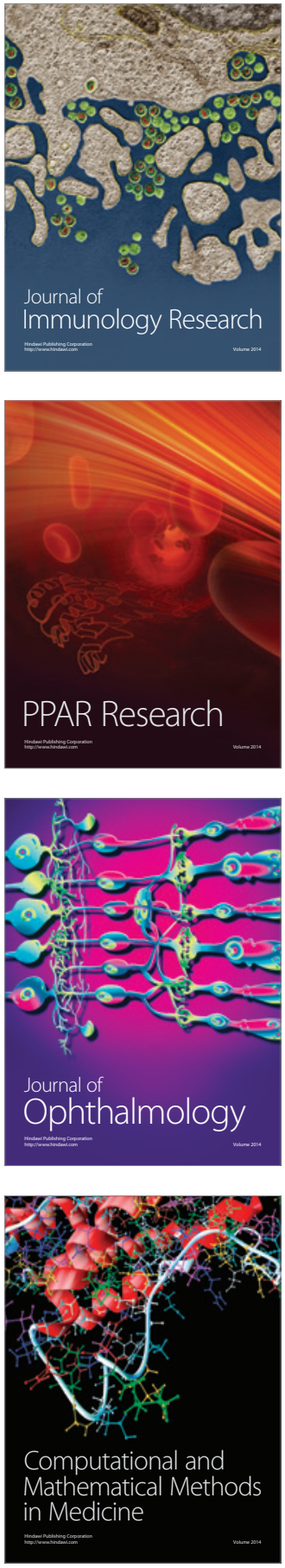

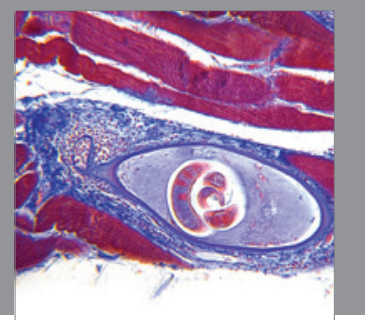

Gastroenterology

Research and Practice
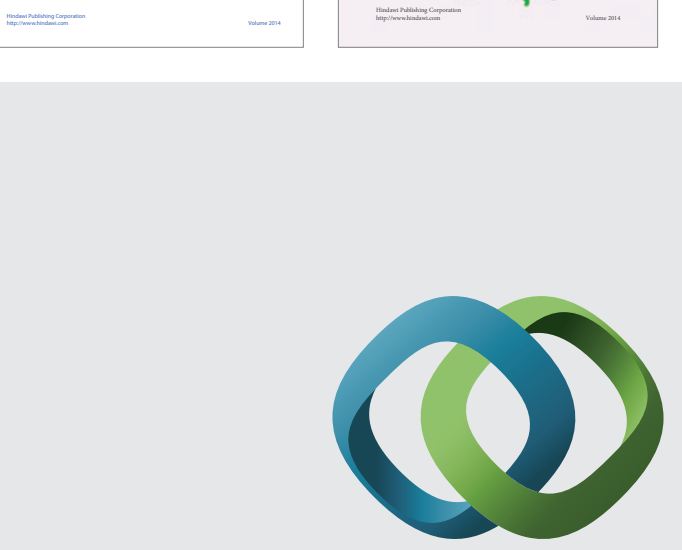

\section{Hindawi}

Submit your manuscripts at

http://www.hindawi.com
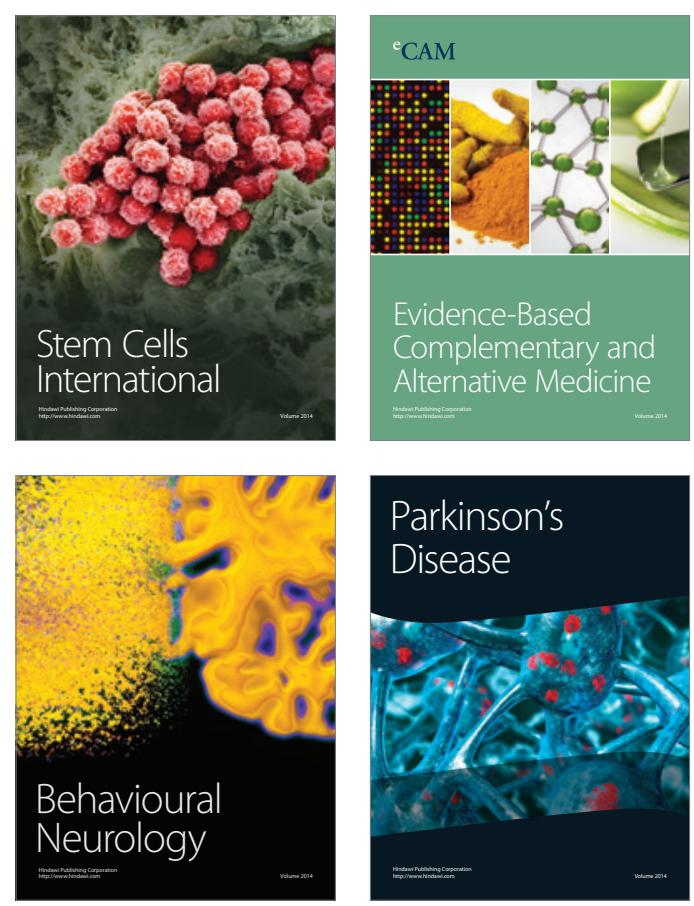

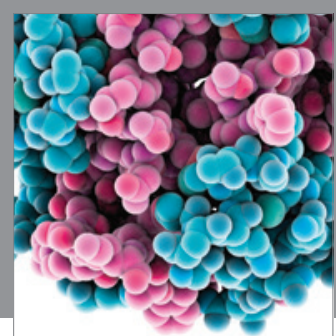

Journal of
Diabetes Research

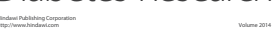

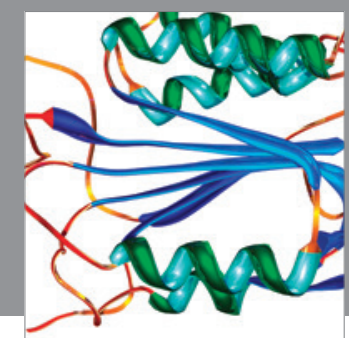

Disease Markers
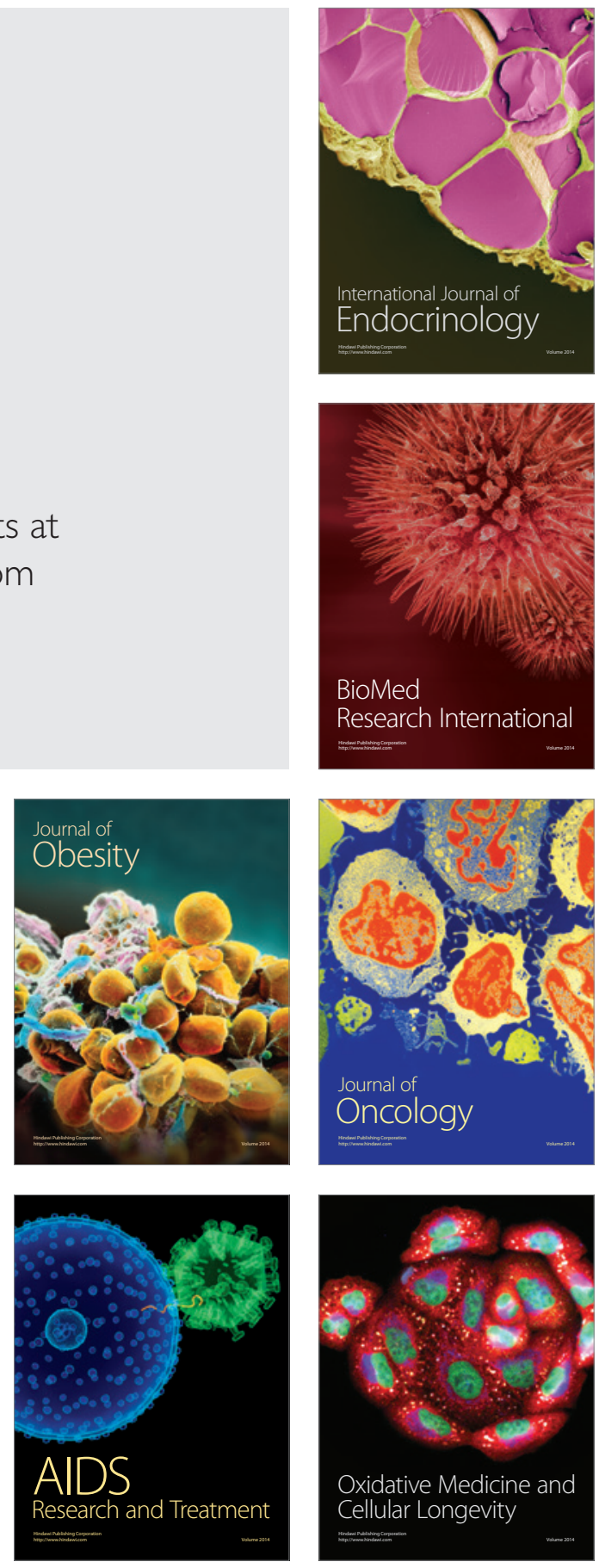